Chapman University

Chapman University Digital Commons

English (MA) Theses

Dissertations and Theses

Spring 5-17-2017

\title{
The Rhetoric of Disability: an Analysis of the Language of University Disability Service Centers
}

Katie Ratermann

rater100@mail.chapman.edu

Follow this and additional works at: https://digitalcommons.chapman.edu/english_theses

Part of the Rhetoric and Composition Commons

\section{Recommended Citation}

Ratermann, Katie. The Rhetoric of Disability: an Analysis of the Language of University Disability Service Centers. 2017. Chapman University, MA Thesis. Chapman University Digital Commons, https://doi.org/ $10.36837 /$ chapman.000025

This Thesis is brought to you for free and open access by the Dissertations and Theses at Chapman University Digital Commons. It has been accepted for inclusion in English (MA) Theses by an authorized administrator of Chapman University Digital Commons. For more information, please contact laughtin@chapman.edu. 
The Rhetoric of Disability: an Analysis of the Language of University Disability Service Centers

A Thesis by

Katie Ratermann

\section{Chapman University}

Orange, CA

Wilkinson College of Arts, Humanities, and Social Science

Submitted in partial fulfillment of the requirements for the degree of

Master of Arts in English

May 2017

Committee in charge:

Ian Barnard, Ph.D., Chair

Brian Glaser, Ph.D.

Jan Osborn, Ph.D. 
The thesis of Katie Ratermann is approved.
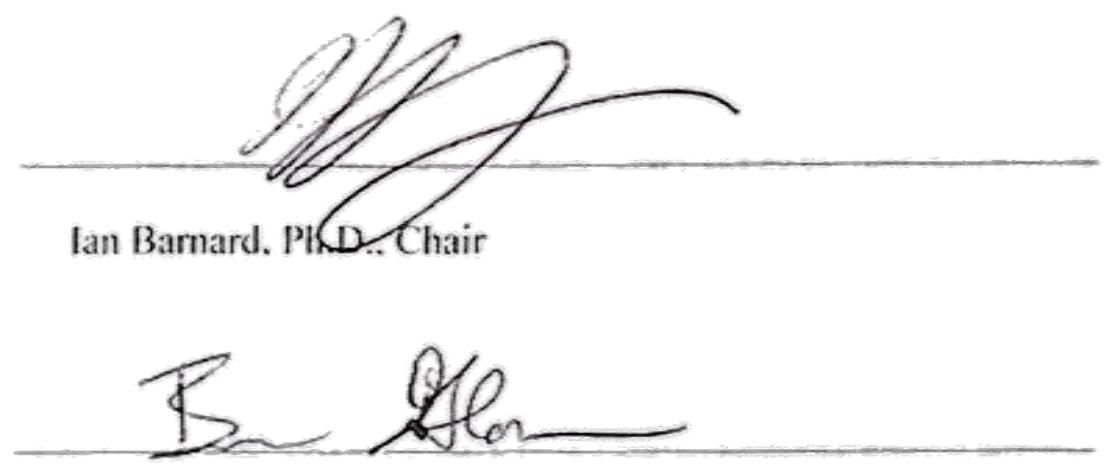

Brian Glaser. Ph,D.

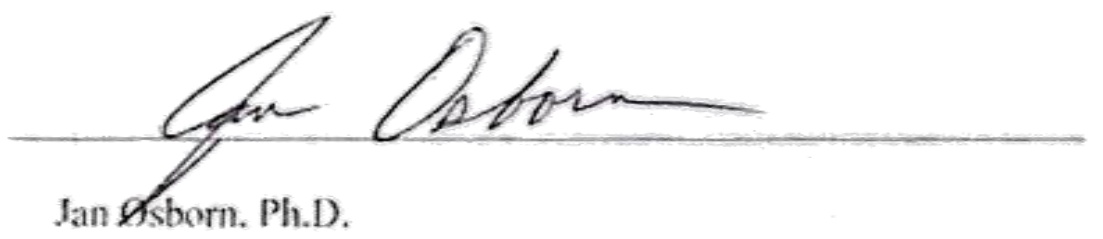

May 2017 
The Rhetoric of Disability: an Analysis of the Language of

\section{University Disability Service Centers}

Copyright @ 2017

by Katie Ratermann 


\begin{abstract}
The Rhetoric of Disability: An Analysis of the Language of University Disability Service Centers

by Katie Ratermann
\end{abstract}

The language on university websites and the policies provided by Disability Services provides material for a rhetorical analysis addressing the marginalization of students with disabilities on college campuses. In this thesis, I discuss the degree to which university distributed texts marginalize students with disabilities. My discussion begins with commentary on Critical Disability Studies, the theoretical influence for this thesis. Following the discussion of theoretical modes in disability studies is a brief commentary on the history of disabilities in academic contexts. After historically contextualizing Disability Services on university campuses, I analyze the rhetoric of San Diego State University (SDSU) and the University of California San Diego's (UCSD) informational texts aimed at students with disabilities, including analysis of how and to what degree information is provided, but also the language of the written policy itself.Through my rhetorical analysis, it is clear that SDSU'svalues are effectively conveyed through language, whereas UCSD explicitly and implicitly separates the Office of Disability Services from disability advocacy. My aim in writing this thesis is to convey the importance of rhetorically sensitive and intentionally constructed language regarding disability and to situate language as a critical factor in creating an inclusive university environment. 


\section{TABLE OF CONTENTS}

Chapter 1: Introduction 1

Chapter 2: A Theoretical Frame for Inquiry 3

$\begin{array}{ll}\text { Chapter 3: Historical Context } & 7\end{array}$

$\begin{array}{ll}\text { Chapter 4: Method } & 13\end{array}$

$\begin{array}{ll}\text { Chapter 5: Analysis } & 15\end{array}$

Chapter 6: Conclusions

$\begin{array}{ll}\text { Works Consulted } & 37\end{array}$ 


\section{LIST OF FIGURES}

Figure 1: image of the home page of SDSU's website

Figure 2: image of the home page of UCSD's website

Figure 3: excerpt from SDSU's required documentation 


\section{Chapter 1: Introduction}

Disability accommodations are not a daily concern for most students on college campuses. A lack of available Disability Services is not debilitating for them, however, for some, disability services are essential. Many universities are not sufficiently providing the resources needed for all students to succeed. For example, in 2015, advocates for the deaf, "file[d] federal lawsuits against Harvard and M.I.T., saying both universities violated antidiscrimination laws" (Lewin). Although federal lawsuits of this caliber are not commonplace, universities failing to adequately accommodate students are. In response to the allegations against Harvard and M.I.T., Lydia Brown, current chair of the Massachusetts Developmental Disabilities Council shared her personal experiences at her Alma Mater, Georgetown University:

[There are] deaf students denied access to ASL interpretation, blind students denied access to Braille materials, students with psychiatric disabilities/mental illnesses coerced into leaving the university and students in wheelchairs functionally prevented from accessing numerous spaces on campus even after recent renovations or new construction post-ADA. (Allen)

Although it is easy for able-bodied people to turn away and ignore the need for more effective Disability Services on college campuses, accessibility is a concern that involves all of society; all of society, knowingly or not, is complicit in the marginalization of people with disabilities.

Regardless of the visibility of the obstacles people with disabilities face or the lack of disability advocacy in mainstream media, it is a grave injustice not to carefully consider the ways in which society creates or alleviates obstacles for people with 
disabilities. It is important to identify disability as a social and cultural construct and illuminate the consequential role of language in marginalizing people with disabilities. Because language contributes to the continuing normalization of the able-bodied at the expense of people with disabilities, converging rhetoric and disability studies is a significant and worthwhile endeavor. Considering the increasing accounts of disabilities on college campuses (NCES 2015),critical thought should be given to the way in which information regarding disabilities and Disability Services are expressed on university campuses.

The language and visual presentations on university websites and the policies provided by Disability Services centers provides material for a rhetorical analysis addressing the marginalization of students with disabilities on college campuses. I conducted a rhetorical analysis of the online sources of information published by Disability Services centers of academic institutions to determine the degree in which university distributed texts marginalize students with disabilities. Following a commentary on Critical Disability Studies, the theoretical influence for this thesis, and a brief discussion of the history of disabilities in academic contexts, I analyze the rhetoric of universities' informational texts aimed at students with disabilities, including analysis of how and to what degree information is provided, and also the language of the written policy itself 


\section{A Theoretical Frame for Inquiry}

Critical Disability Studies ascribes to a social model of disability rather than a medical or individual one. Instead of viewing disability as a medical or biological phenomenon, Critical Disability Studies views disability as a social construct. Persons with disabilities may experience functional limitations that non disabled persons do not experience, but the biggest challenge comes from mainstream society's unwillingness to adapt, transform, and even abandon its 'normal' way of doing things. (Pothier and Devlin 13)

While disabilities are sometimes caused by or related to a situation of the biological or medical variety, it is important to understand disability not as purely a medical issue because, to a large degree, socialization constructs the ways in which mainstream society views people with disabilities and the way in which people with disabilities experience the world. For example, in regard specifically to mental disabilities (learning disabilities, psychological disorders, etc.), "stigma remains the number one barrier to students seeking help," according to participant responses and data gathered in a survey conducted on college campuses by the National Alliance on Mental Illness (Gruttadaro and Crudo, 15). Common perceptions of people with disabilities are often based on negative depictions which cause stigma. Margaret Price comments on how negative labels like "crazy," are insensitive, inappropriate, and serve as rhetorical reminders of the work that still has to be done in order to reverse the negative associations often automatically made of people with mental disabilities The negative stereotypes she addresses are not new phenomena; they are constructions that have been reinforced by discourse across a long history of oppression toward people with mental disabilities. 
The idea that historical and contemporary depictions of people with disabilities contribute to the normalization of the able-bodied often at the expense of people with disabilities also expands to all types of disabilities. For example, terms like "crazy" reinforce negative stereotypes of people with mental disabilities as "a homeless person muttering on a bus; a figure lying restrained on a hospital gurney; or a dull medicated gaze" (Price 1). Similarly, terms like "handicapped" or "crippled" reinforce negative stereotypes associated with people with physical disabilities. Just as people with mental disabilities face stigma fueled by misconceptions and negative depictions, people with other kinds of disabilities experience similar difficulties —obstacles created by society.

Although a person's disability can cause very real and challenging obstacles, Critical Disability Theory focuses on the idea that, "the person with the disability is not the problem. Rather, it is the pervasive impact of ableist assumptions, institutions, and structures that disadvantage persons with disabilities" (Pothier and Devlin 13). If viewing disabilities as a biological phenomenon, Disability Services will always be limited to merely providing accommodation to help people with disabilities to survive in an ableist society. Critical Disability Studies allows for critique of the socially constructed obstacles people with disabilities face and aims to provide education to communities at large to prevent ableist, "assumptions, institutions, and structures." It is because Critical Disability Studies understands disability as a social construct that commentary on how to best create inclusive language and academic spaces is possible. An analysis of language and rhetoric (societal constructions) depend on the acceptance of a social model of disability. 
In an effort to acknowledge the full spectrum of obstacles people with disabilities face, it is essential to provide a commentary on the existing, conflicting social and individual models of disability to reconcile them for the purposes of argument. While the social implications of disability can be devastating, it is harmful to assert a social model of disability that does not take into account the very real and valid difficulties people with disabilities face. Much of the criticism surrounding Critical Disability Studies has referenced the notion that a social model of disability invalidates the individual experiences of people with disabilities. However, Mike Oliver, who coined the phrase "social model of disability," explains two convincing reasons why a social model is more beneficial than an individual model. He states that an individual model, "locates the 'problem' of disability within the individual and secondly it sees the causes of this problem as stemming from the functional limitations or psychological losses which are assumed to arise from disability" (2). A social model of disability can recognize the unique difficulties that individuals with disabilities face without asserting that the characteristics of the disability or the person with the disability are the problem. For example, if considering a person who uses a wheelchair, a social model of disability can identify the ways in which society does not allow for the person to maneuver human constructions as easily as a person who walks. To offer a very simplified example, the problem is that most buildings include stairs and not a ramp at the forefront; the problem is not that a person who uses a wheelchair may not have the capacity to walk up stairs. In a more general sense, an individual model may focus on the obstacles caused by and the characteristics of a particular disability, but not necessarily the ways in which society shapes those obstacles or how society can better provide for people with disabilities. 
In the context of academic institutions, a social model approach would advocate for Universal Design, not only in physical constructions but also in instructional practices. Universal Design allows for a variety of instructional methodologies, "in the ways information is presented, in the ways students respond or demonstrate knowledge and skills, and in the ways students are engaged" (UDL). By catering to the varied needs of unique students, Universal Design is a concept that, "reduces barriers in instruction, provides appropriate accommodations, supports, and challenges, and maintains high achievement expectations for all students, including students with disabilities" (UDL).Universal Design includes measures that refer specifically to accessible learning, not just accessible physical spaces; Universal Design Learning shifts the focus from the perceived inabilities of students with disabilities to the failings of institutions and practices which do not adequately provide accessible learning strategies to all students. This thesis is dependent on a social model of disability, which can be seen not as ignoring the individual difficulties people with disabilities face, but restructuring the way we think about disability to resist seeing disability as an individual "problem" and allow for more inclusive spaces. 


\section{Historical Context}

Although a relatively new discipline, Critical Disabilities Studies is steadily growing; in the context of postsecondary education specifically, issues regarding Disability Services continue to be significant and examinations of practices and policy regarding students with disabilities is necessary. According to the National Center for Educational Statistics (NCES 2011), the number of students with disabilities attending a four year university in 2011 was 2,563,000, making up $11.1 \%$ percent of university students." While a population of this number is significant enough in and of itself to warrant further study on improving inclusive practices for students with disabilities, the number of students attending four year universities with unreported disabilities is potentially much higher than the $11.1 \%$ statistic from NCES might suggest. According to a 2011 study from the American Academy of Pediatrics, the "prevalence of any developmental disability increased from $12.84 \%$ to $15.04 \%$ over 12 years" (Boyle et. al.), but reported disabilities did not. The discrepancy may be due to student's' hesitance, "to disclose to the college or University that they have a disability, in part because of the anticipated negative consequences of that action [or] worry that accommodations will give them an unfair advantage, or that it will appear to others that they are not competitive" (Trammell). A 2013 study concluded that, "stigma is significant to the degree that colleges and universities, and specifically the [Disability Services] offices, should be targeting resources and programming specifically to reduce disability-related stigma" (Trammell). It is not inconceivable to suggest more students might report their disabilities if stigma was reduced in university settings or that the amount of unreported disabilities in academic institutions is significant. 
It is not surprising that some students today feel stigmatized because of their disabilities; negative perceptions of people with disabilities persist even after the condemnation of acts committed against people with disabilities throughout history. Prior to the Second World War, people with disabilities were generally regarded as incapable or burdensome. Many were abandoned by their families, forced to endure neglect or abuse while hospitalized, or even forcibly euthanized under the Nazi regime(USHMM). Disability Services is a fairly recent concept which did not gain considerable traction until following World War II.

Attention directed toward increasing Disability Services gained more support following the passing of the GI Bill (Serviceman's Readjustment Act of 1944); with an increased number of veterans (many with disabilities) attending college, academic institutions began making more accommodations for students with disabilities. Veterans served as a catalyst for change and continued to substantially affect the development of Disability Services; however, the 1960's with the civil rights movement and educational reform was an era of notable expansion of Disability Services (Madaus). In 1962, Herbert Rusalem, an early advocate for Disability Services, predicted that the population of students with disabilities on college campuses would continue to increase:

Physically handicapped college students requiring one or more special educational services are no longer a rarity on the American campus. Having the same goals as other students, they are enrolling in increasing numbers, encouraged by better public and private school preparation, improved rehabilitation services, the availability of scholarship funds, and a changing attitude toward disabled persons in our society. Since these sources of 
encouragement will probably become more influential in the future, it seems likely that the problems of educating the physically handicapped student will be receiving increasing attention. (161)

Rusalem's prediction ended up being correct; increasing attention was given to students with various categories of disabilities. In 1963, the term "learning disability" was first introduced, and consequently, services for students with invisible disabilities were developed and students with recognized disabilities increased dramatically (Hallahan and Mercer).

Development of Disability Services did not end in the 60s; in 1975, Congress passed the Education for All Handicapped Children Act, "to support states and localities in protecting the rights of, meeting the individual needs of, and improving the results for ... infants, toddlers, children, and youth with disabilities and their families" (Rhodes). This law was later revised in 1997 and renamed the Individuals with Disabilities Education Act (IDEA) as it is referred to today (Rhodes). The 1970s was a decade of landmark events for Disability Services. The Vocational Rehabilitation Act of 1973 made disability based discrimination illegal in all federally funded programs:

No otherwise qualified handicapped individual in the United States shall, solely by reason of his handicap, be excluded from participation in, be denied the benefits of, or be subjected to discrimination under any program or activity receiving Federal financial assistance. (U.S. Code 794)

Section $\mathrm{E}$ of the act specifically refers to postsecondary institutions and requires them to consider applications of all qualified individuals regardless of disability status as well as provide necessary accommodations for students with disabilities (Feldblum 12). 
Anothersignificant milestone was the first Disability Services conference, the "Disabled Students on American Campuses: Services and State of the Art" in 1977. This conference established Disability Services as a profession in higher education (Madaus 10). Additionally, a committee formed at this conference later went on to found the professional association known today as the Association on Higher Education and Disability (AHEAD).

In 1990, the landmark Americans' with Disabilities Act (ADA) was enacted as the country's "first comprehensive civil rights law addressing the needs of people with disabilities, prohibiting discrimination in employment, public services, public accommodations, and telecommunications" (The Americans With Disabilities Act). The passing of ADA, as it is commonly known, required construction standards to provide for accessibility in public spaces, but it also led to program developments that allow students with disabilities access to higher education. In addition, the 1990s were an important time for the development of key concepts in Disability Services such as Universal Design which has expanded to include accessibility in curriculum as well as accessibility in physical spaces; it remains a crucial component of modern Disability Services today.

Critical steps toward promoting inclusivity and altering the negative misconceptions of people with disabilities also occurred in the early 90s when the term "handicapped" fell out of fashion. Due to criticism from advocacy organizations and people with disabilities, the term was "rejected when disabled people began wresting the power of the programs that controlled their lives from social workers and began to run their own programs...if for no other reason that it was a term imposed on them by agencies" (Nelson 28). This marked the beginning of attention to the actual words used to 
describe disabilities and people with disabilities. Following the recognition of "disability" as the acceptable term, other offensive terms for people with disabilities ("cripple," "lame," "retard," imbecile," "dumb," etc.) have received scrutiny. In 2013, the federal government announced they were officially, "replacing the term 'mental retardation' with 'intellectual disability' in our Listing of Impairments ... This change reflects the widespread adoption of the term "intellectual disability" by Congress, government agencies, and various public and private organizations" (Federal Register). Official recognition of the importance of using acceptable terms to refer to disabilities is a first step in alleviating some of the stigma that people with disabilities face. As Disability Studies continues gaining support and advocating for inclusivity, the rhetoric used to discuss disability may improve.

Although the last 50 years has seen immense improvement in the way society views disability and the increased efforts to provide adequate accommodations, disability service departments can be improved further. An especially pressing concern is a lack of funding:

Higher education is a business. And like any other business, it strives to offer a quality product at a reasonable price. But in a bad economy...colleges face a double problem: their endowment is reduced, and the demand for scholarship funds increases...Some obvious considerations for the school are to increase resources for programs that are bringing in revenues (students and research) and to shrink areas that don't show obvious economic advantages. (Kadison 164) According to a Survey of College Counseling Center Directors, some of the biggest problems they face include, "financial concerns," "insurance issues," and a lack of 
available counselors and psychiatrists, lack of a full time administrative staff, and lack of funding" (Kadison 166). Because funding for Disability Services is so scarce among postsecondary institutions, universities who make a significant effort to fund Disability Services value the work they do and understand the needs of their students. 


\section{Method}

To combat a lack of funding, some academic institutions rely on federal or state grants to fund their Disability Services Departments. Workability IV is a state funded program managed by the Department of Rehabilitation, and TRiO is a federal grant provided for the implementation of programs and activities on postsecondary campuses. One institution that qualified and received both these grants is San Diego State University (SDSU). TRiO can be awarded in order to implement services aimed at a variety of populations, but SDSU's funding is for the development of services for students with disabilities. TRiO is documented as funding for programs and activities designed for traditionally underserved populations:

students who are limited English proficient, students from groups that are traditionally underrepresented in postsecondary education, students with disabilities, students who are homeless children and youths, students who are in foster care or are aging out of foster care system or other disconnected students. ("Educational Opportunity Centers")

SDSU's funding is specifically used to benefit students with disabilities, which is not common among TRiO grantees.

Because SDSU has received both a Workability IV and TRiO grant which necessitates accessible information regarding their programs related to students with disabilities, the contents of SDSU's website will serve as one source for analysis. Further justifying SDSU as a choice for analysis, its website states, "Student Disability Services at SDSU serves over 1,472 students with visible and invisible disabilities," which shows not only the prevalence of Disability Services administered, but also the value SDSU 
places on transparency as well as the Disability Services Department. For comparison purposes, I will also analyze The University of California, San Diego (UCSD), which does not have any advertised grant funding specific to disabilities. UCSD was chosen because of its similar size and close proximity to SDSU, to rule out variances due to student body size or geographic factors. With 29,046 undergraduates enrolled in 2015 at SDSU and 28,127 undergraduates enrolled in 2016 at UCSD, the schools are comparable in size, but not necessarily in the quality or quantity of Disability Services offered. SDSU lists twenty staff members working in the Disability Services Department while UCSD only lists seven. Despite fairly similarly sized student bodies, the two Offices of Disability Services have an uneven staff to student ratio and express very different mission statements. 


\begin{abstract}
Analysis
Because mission statements are ever-present in academic and institutional documents, the mission statements of SDSU's and UCSD's Offices of Disability Services provide a salient place to begin an analysis. Although mission statements are common, a study of 112 university mission statements found the majority of statements to be, “amazingly vague, vapid, evasive, or rhetorical, lacking specificity or clear purpose...full of honorable verbiage signifying nothing” (Newsom and Hayes 29). While Newsom and Hayes argue that the majority of the mission statements in their study "signify nothing" and neither include a connection to actual student learning expectations nor provide opportunities for future strategic planning, mission statements still hold rhetorical power. Whether intentional on the part of the author or not, mission statements can convey messages other than the mission of the organization and/or convince a reader of a particular conception or misconception regarding people with disabilities and disabilities on college campuses. Therefore, it is important for university officials to construct mission statements with sensitivity to their rhetorical properties and with honest and astute intentions.
\end{abstract}

The Association of Higher Education and Disability (AHEAD) recognizes the significance of how mission statements are constructed and, accordingly, provides resources to aid offices of Disability Services in writing mission statements. One such resource AHEAD provides is the display of numerous sample mission statements, such as this example:

In conjunction with the Community Principles and overall mission of the university, the Office of Disability Services appreciates disability as an integral 
part of the University experience. We are committed to providing equal access and opportunity to all campus programs and services for persons with disabilities. Through collaboration and support of the entire campus community, Disability Services promotes disability pride, self-determination of the student, and universally accessible design principles, so that everyone has full access to University life.

It is important to note that this sample mission statement conveys inclusivity in the way it begins by explicitly asserting disability as, "an integral part of the University," rather than separating students with disabilities from students without documented disabilities. The inclusive phrasing continues throughout the statement with phrases like, "We are committed to providing equal access and opportunity to all campus programs" and "Through collaboration and support of the entire campus community." The use of diction such as "all" and "entire" create a sense of unity among the whole of a college campus, including students with disabilities. In addition, the use of the first person plural, "we" is universalizing and resists creating a hierarchy between the employees of the Office of Disability Services and the students with disabilities that they serve.

In considering the language of the mission statements of SDSU and UCSD, the schools chosen for this study, SDSU shares many similarities with AHEAD's sample statement:

Student Disability Services (SDS) provides qualified students with disabilities equal access to higher education through academic support services, technology, and advocacy in order to promote their retention and graduation. To further this mission, SDS is committed to the following: minimizing academic and physical 
barriers for students with disabilities, promoting self-advocacy within students with disabilities, working collaboratively with SDSU faculty, staff, and the campus community to increase disability awareness.

In some ways, SDSU's mission statement is similar to the sample statement. For example, the SDSU statement declares its commitment to "increasing disability awareness" among the "campus community" while the sample emphasizes the importance of the, "collaboration and support of the entire campus community." SDSU's statement expresses the goal of, "promoting self-advocacy within students with disabilities" while the sample statement "promotes disability pride," and "self-determination of the student." Both SDSU and the sample express the mission of removing barriers, providing accommodations, but also emphasizing community education, three goals deemed essential in creating a successful Disability Services Department by Jason McAlexander, the Director of Disability Services at my home institution, Chapman University.

However, although SDSU's mission statement shares many conceptual similarities with the sample statement, they are not created equal in terms of language. Unlike the sample statement, SDSU's mission statement is written in a third-person point of view with the Student Disability Services as the main agent or the subject in focus. For instance, the goals of the SDS are written in terms of the actions of the SDS rather than the proposed student outcomes. SDSU's statement contains phrases that convey the notion that Disability Services are exclusively relevant to students with disabilities and insinuate an implicit inferiority of students with disabilities. For instance, the statement is written in terms of what SDS can do for students with disabilities; it includes phrases, such as "provides qualified students with disabilities equal access... promote their 
retention and graduation...minimizing academic and physical barriers for students with disabilities." Each of these phrases are structured with SDS as the subject of the sentence and the predicate as an action SDS aims to take to make up for an implied deficit or inability of students with disabilities.

While SDSU's statement aims to minimize "physical barriers for students with disabilities," the sample statement is phrased as aiming to promote, "universally accessible design principles, so that everyone has full access to University life." SDSU's phrasing insinuates that physical barriers are only a problem for students with disabilities and that students with disabilities require a change to the modus operandi. With any normalization (an environment with physical barriers), anyone or anything outside of the constructed norm is othered. In addition, SDSU's statement isolates students with disabilities by referring to them as separate from the community. The final sentence of the statement is constructed as a list of three commitments: "minimizing academic and physical barriers for students with disabilities, promoting self-advocacy within students with disabilities, working collaboratively with SDSU faculty, staff, and the campus community to increase disability awareness." The structure, with the first two items in the list ending with "students with disabilities" and the last item explicitly mentioning all populations of a campus community except for students with disabilities, conveys a message that students with disabilities are not included in the campus community. This erasure not only isolates students with disabilities,it also fails to recognize the importance of including students with disabilities in fostering disability awareness and promoting disability education among every facet of a university. By shifting to language that conveys Universal Design, as seen in the sample statement, and avoiding phrases that 
isolate students with disabilities, mission statements can serve to explicitly state the aims of a Disability Services Center, but also rhetorically support stated goals.

Unlike SDSU, UCSD does not have an explicit "mission statement" on their Office for Students with Disabilities website. However, the front page of their "About Us" section reads:

The Office for Students with Disabilities (OSD) at UC San Diego works with undergraduate, graduate, and professional school students with documented disabilities, reviewing documentation and, through an interactive process with the student, determining reasonable accommodations.

It is perhaps not entirely reasonable to analyze this statement with the same scrutiny used to assess constructed, intentional "mission statements"; however, it is significant to note the lack of a mission statement and the fact that nowhere in the above statement or anywhere on the UCSD website is disability awareness, Universal Design, or community involvement mentioned. The statement above, which most closely reflects a mission statement, merely states in simple terms the accommodations process, which suggests that UCSD's Office for Students with Disabilities may be more interested in a reactive approach than a proactive approach when it comes to providing for students with disabilities. Limiting Disability Services to providing accommodations for existing obstacles does little to prevent future obstacles or alleviate the actual obstacles, rather accommodations are merely responses to the hardships caused by an obstacle. A more effective mission statement and goal of a Disability Services center would focus on implementing universal design and working toward eliminating the actual obstacles, rendering future accommodations unnecessary. 
The notion that UCSD's OSD is primarily focused on providing accommodations over other Disability Services is further supported in OSD's own brochure. The brochure explicitly states, "the OSD is not an advocacy agency, academic advising center, or counseling center." In addition, the brochure also emphasizes the necessity of making sure, "potential accommodations will not fundamentally alter or modify the nature of the academic environment." Because of the lack of mission statement or mention of universal design, the declaration of the OSD as "not an advocacy agency," and the expressed desire to maintain the status quo of the "academic environment," UCSD's Office for Students with Disabilities, as represented by their online content, does not advocate for students with disabilities or working toward a more universal environment for the success of all students but, rather, focuses primarily on providing accommodations for students with disabilities to function within the existing university structure. To not look critically at the structure of an institution or alter the academic environment in which students with disabilities seek accommodations, promotes the erasure of the voices of students with disabilities. The adherence to a system which does not include students with disabilities forces a student with disabilities to conform to an able-bodied standard which is not only inappropriate, but also sometimes impossible. Advocacy and alterations to existing structures are essential for progress, and the most beneficial mindset is one that values changing the source of a problem in addition to reacting and providing solutions.

The organization of the school's website offers insight on each of the college's existing structures by providing a piece of visual rhetoric, an object intentionally created to communicate a certain set of information, for analysis. One modern conceptualization of visual rhetoric is as a "communicative artifact...the actual image rhetors generate when 
they use visual symbols for the purpose of communicating. It is the tangible evidence or product of the creative act, such as a painting, an advertisement, or a building" (Foss 304).In this case, the "communicative artifacts" are the websites, created to communicate information regarding the school and Disability Services. The link to the Disability Services page is visible on SDSU's main homepage; the link is located at the top of the website in line with the categories, " Future Students," "Current Students," "Faculty/Staff," and "Alumni."

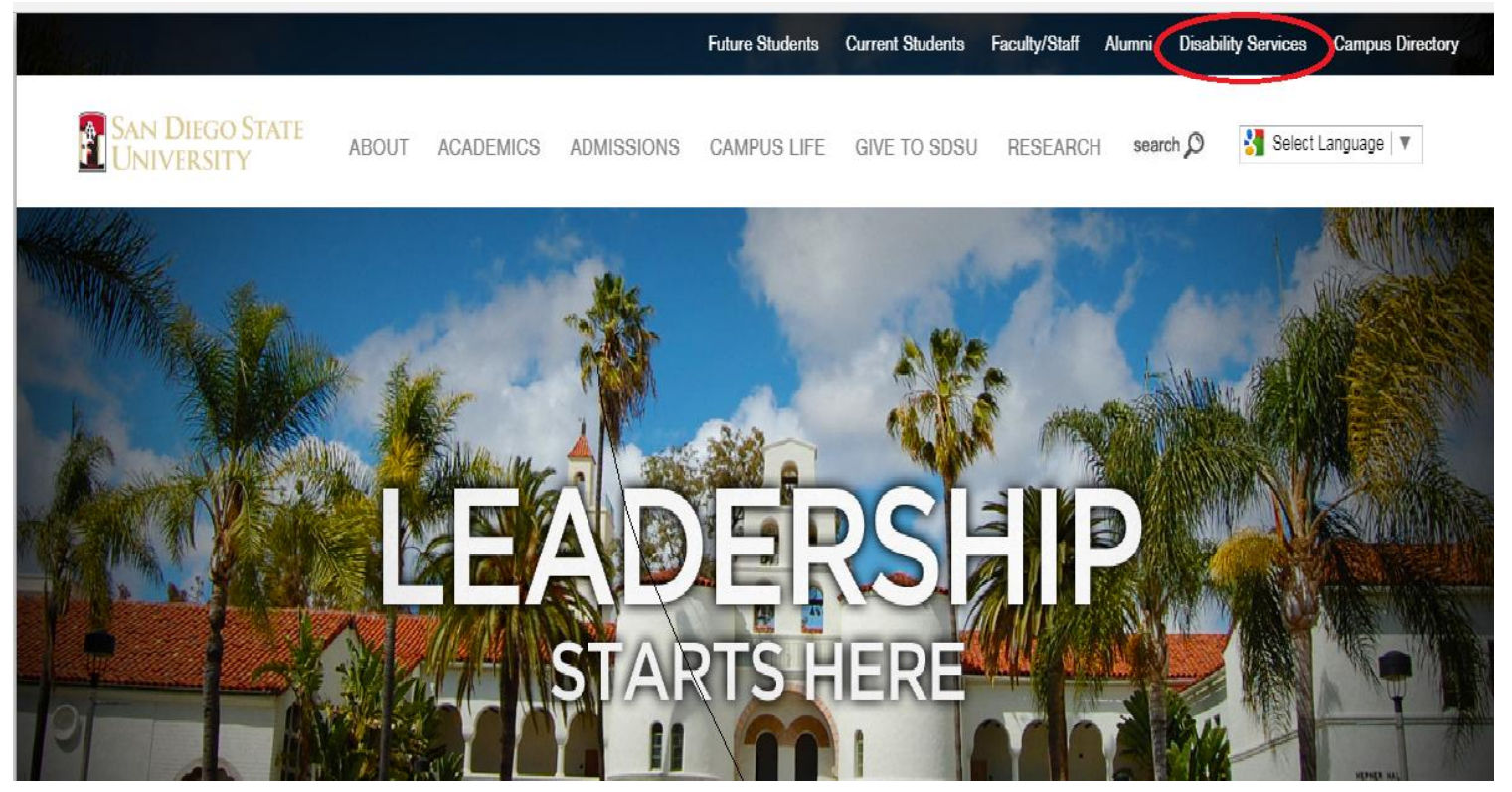

Figure 1: SDSU's homepage with the link to the Disability Services page indicated with a red circle, in line with "Future Students," "Current Students," "Faculty/Staff," and "Alumni."

In contrast, UCSD's Office for Students with Disabilities link is not visible on the homepage; in order to access a direct link, a user would need to scroll to the bottom of the website where there is a list of links as part of a site index written in a light grey and 
in a typeface smaller than the text on the rest of the website.

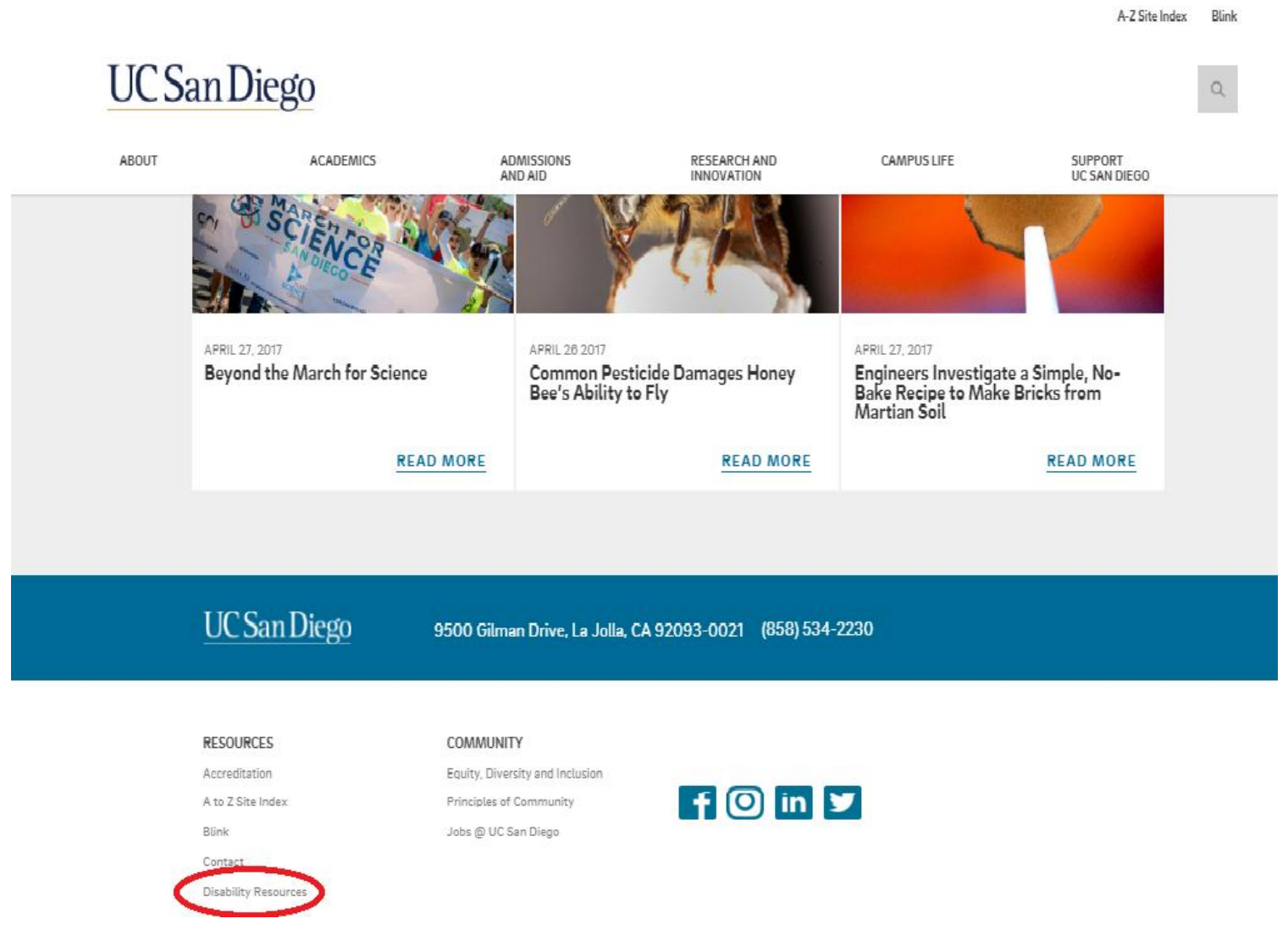

Figure 2: UCSD's homepage, after scrolling to the bottom. The link to the disability resources page is indicated in a red circle, underneath the site index in a small, light grey font.

If not utilizing the site index, a user would have to click, at minimum, four links in order to arrive at the OSD's page. The placement of the Disability Services links communicates the value or lack thereof each institution holds for Disability Services. SDSU places the link at the forefront of their site which signifies importance; UCSD's link, buried under multiple drop down menus, situates Disability Services as secondary to other services listed on the website's main menu. Additionally, SDSU's link is placed in line with other populations on campus which conveys the idea that students with disabilities are equally important as, not only students without disabilities, but also faculty members, alumni, etc. The apt and intentional organization of SDSU's website demonstrates how the placement 
of symbols can connote inclusivity and promote diversity on a campus as a whole in an effort to normalize people of all abilities and provide the most inclusive college experience possible for students with disabilities. The accessibility of the Disability Services website in relation to a school's website as a whole affects the way a student will interact with Disability Services and the remainder of campus. The content on the Disability Services website also has the potential to greatly affect a student's educational experience.

For many students, content found on a school's website may be the first exposure they have to information regarding the Office of Disability Services. Because online material is potentially the content by which students may form first impressions of a Disability Services Department, it is especially important to intentionally and sensitively craft the language on documentation made available to students online. One such area of online content that is common to both SDSU and UCSD's Office of Disability Services website is information regarding how to initially acquire accommodations. Both schools require a similar process, including a student intake form, proper documentation, and an in-person meeting with a counselor to ascertain the appropriate accommodations on an individual basis. The process, although similar, is expressed with different language.

San Diego State University goes to great lengths to both inquire about each student's individual needs and provide adequate information to students about how to navigate the accommodations process. There are explicit guidelines written and posted specific to each of the following categories: Learning disabilities, AD/HD or psychological disabilities, deaf or hard-of-hearing, visual limitations, physical disabilities that are mobility or health-related, or disabilities related to acquired brain injury. When 
applicable, the next step in the process is a student questionnaire specific to a student's category of disability. The questionnaires are nine pages in length and include a combination of multiple choice and free response answers. On the questionnaire related to psychological disabilities, there are specific, focused, multiple choice questions, such as

Check any of the following which present difficulties in your test taking experience: anxiety, insufficient time, multiple choice, true/false, matching, fillin, short essay, long essay, calculations, spelling, grammar, organizing, memory, background noises, distraction, filling out scantron (bubbling)

There are also, open-ended, free response questions, such as "describe as completely as possible the learning difficulties that you have experienced throughout your lifetime" followed by ample space to write. The inclusion of specific questions is practical and efficient in that it allows Disability Services' staff to get an idea of the difficulties students face, specifically in regard to their present classes. It also prompts students and gives them options in the event they don't feel they know what to write on their own. In contrast, the free response questions serve an equally important purpose of encouraging free expression, which shows that the Disability Services Department values students' experiences and allows for amplification of students' authentic voices.

The diction of the SDSU student questionnaire establishes a friendly tone even before a student has the opportunity to interact with a counselor in person. The choice to include colloquial, personal phrases, such as "In order to learn more about you" and multiple instances of the word, "please," serve to break down the hierarchy traditionally associated with a staff/student relationship. By using colloquial language that insinuates a 
genuine interest in a student, the questionnaire, although an impersonal form, attempts to situate the student filling out the form as an individual as much as possible. The use of "please," in addition to providing basic courtesy, connotes the idea that the student's time and effort is valuable and in turn disrupts any imposed hierarchy between staff and student by situating them as equals working together, rather than as a staff member servicing an in-need student.

UCSD's intake form is general and abbreviated in comparison to SDSU's form. Totaling only three pages, UCSD's form includes mainly biographical information and asks the student to answer, "What do you believe is your medical issue" and to list, "the accommodations you are currently requesting." This method of asking a student to identify their disability and required accommodations places all the responsibility on the student, which does not express a desire to work together with a student. It is also much less individualistic than asking about a student's specific symptoms and needs; instead of providing accommodations according to individual needs, this line of questioning insinuates a method of providing accommodations based on diagnosed disability which disregards the individual and differing experiences of people with the same disability diagnosis. By focusing on a diagnosis, the form also excludes students who may be experiencing complications due to a disability for the first time or students who have a disability but have never received medical treatment. Excluding identifying or introductory, biographical questions, ten out of a total of fourteen questions on the form refer to past or present diagnoses, prescriptions, medical treatments, or accommodations. The remaining four questions are vague, such as, "describe any other issues in your life that may be currently affecting your academic performance." Because the emphasis of the 
questionnaire is on ascertaining past and current opinions of medical professionals rather than the experiences of a student, the form is not only invalidating to a student with no prior medical treatment, but also creates a tone that insinuates students must prove the validity of their diagnosis or provide evidence for their need for accommodations.

UCSD's brochure for the Office of Disability Services, like the student intake form, does not utilize a collaborative tone or express the desire to work together with students as seen in SDSU's documentation. UCSD's brochure states, "common reasons you may not get what you want" followed by a bulleted list of "reasons." By including this section in the brochure- especially because it is phrased as a negative statement rather than a positive one- - the first impression students may form of the Office of Disability Services is that student accommodation requests are often not met. The phrasing of "what you want" can be interpreted as invalidating to the needs of a student with disabilities. "Want" connotes that accommodation requests are frivolous or not necessities - that students requesting accommodations are acting on wants rather than genuine needs. To avoid an accusatory tone, the syntax of UCSD's statement, "reasons you might not get what you want" could be restructured in a way that does not focus on a negation. For example, instead of listing reasons student sometimes do not receive the accommodations they are requesting, SDSU lists detailed guidelines for how to determine appropriate accommodations and the necessary steps required to most effectively request those accommodations.

SDSU's website provides information for both students with disabilities and their medical professionals. Information is provided in the form of written guidelines and a checklist for students that is specific to each category of disability and includes specific 
language. The guideline for psychological disabilities, for example, includes the four required pieces of documentation, the purpose of each document in determining eligibility, and a list of recommended procedures for completing each piece of documentation properly. The information provided specifically to students seeking accommodations for Attention Deficit/Hyperactivity Disorder outlines clearly in a numbered list which documents are required and offers recommendations for instruments most likely to fulfill the Office of Disability Service's requirements. Similarly, SDSU's Disability Verification form, which is completed by a licensed medical professional, provides a list of required documentation and recommended instruments for completing necessary testing. It is also important to note that SDSU's guidelines are catered toward specific types of accommodations, rather than a uniform document for every student seeking accommodations. The distinctions between types of disabilities, including "invisible" disabilities, helps display how the Office of Disability Services views each student as an individual and not just one of many.

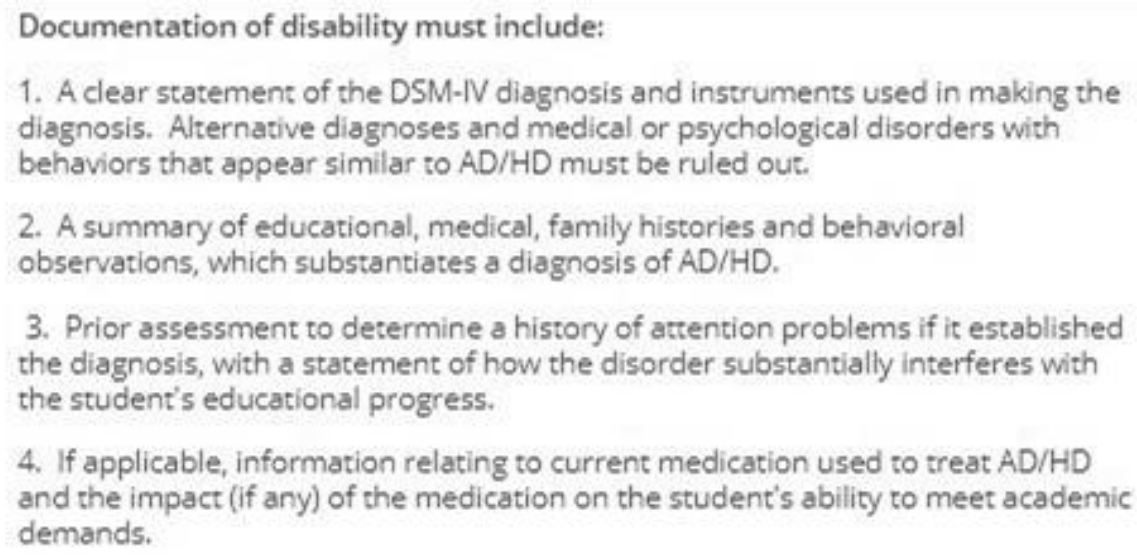

Figure 3: Short excerpt from over five pages of information on SDSU's required documentation for students with $\mathrm{AD} / \mathrm{HD}$ 
In contrast, UCSD's website does not provide guidelines for students regarding acceptable forms of documentation. The required Documentation Form also does not include specific instructions for the medical professional completing the form. While SDSU's form includes a numbered list of all required documents, UCSD's form merely states, "Please include copies of any relevant adult normed psycho-educational or neuropsychological assessments, including test scores." The lack of explicitly stated requirements on UCSD's website is especially problematic in consideration alongside the previously mentioned reasons students "may not get what [they] want."

UCSD lists in the Office for Disability Services brochure the reasons why students "may not get what [they] want":

- Your documentation does not clearly outline your current functional limitations and/or you are unable to articulate your current functional limitations when engaging in the interactive process with a disability specialist;

- Your accommodation request is not appropriate given your current functional limitations;

- Your accommodation request would fundamentally alter or modify the nature of the class, lab, or academic environment;

- Your accommodation request would violate applicable laws.

The choice to write these reasons in second person automatically creates an accusatory tone; the failing to acquire proper documentation, for example, is attributed solely to the individual reader as opposed to a more generalized audience (i.e., students). To insinuate the student is at fault for not having documents that "clearly outline...current functional limitations" is to place fault on a party without agency in the matter. The medical 
professional is responsible for completing documentation for the student and nowhere at the ODS online site are there guidelines for what is considered appropriate documentation, for the student or the medical professional.

The responsibility is further placed onto the student with the conclusion of the first point: "you are unable to articulate your current functional limitations when engaging in the interactive process with a disability specialist." This places the responsibility of determining both symptoms and necessary accommodations on students, as well as excluding students who have trouble articulating their ideas, including students who may have trouble because of their disability. The second and fourth point discuss the necessity of requesting appropriate accommodations, yet nowhere is information regarding appropriate accommodations or "applicable laws" made available to students. Because these statements contradict the lack of information provided elsewhere, both are at best, frustrating, and at worst, rendered meaningless. With underlying messages that do not support one another, it becomes clear that the language utilized on UCSD's website does not accurately portray the values of the Office of Disability Services. Finally, the statement, "your accommodation request would fundamentally alter or modify the nature of the class, lab, or academic environment" is not inclusive to students with disabilities. The statement shows that the institution places more value on maintaining the status quo than providing access to all students. If the "the nature of the class, lab, or academic environment" would be altered by a student's accommodations, then it is appropriate to consider why the nature of the class is inherently exclusive to students with disabilities, not exclude individuals from access. 
Just as it is important for medical professionals to have adequate information to most effectively provide for students with disabilities and fulfill the school's requirements, it is necessary for a school's faculty to have access to educational resources regarding students with disabilities. The University of Connecticut's Center on Postsecondary Education and Disability, a national leader in disability research and provider of the Postsecondary Disability Training Institute, advocates for resources for faculty, promotes Universal Design in instructional practices, and argues, "by providing faculty with a framework and tools for designing inclusive college instruction, the dialogue surrounding college students with disabilities changes from a focus on compliance, accommodations, and nondiscrimination to an emphasis on teaching and learning" (Scott et. al.). Proactively implementing Universal Design instruction eliminates some of the need for reactive measures such as, "compliance, accommodations, and nondiscrimination." If faculty members and educators are provided adequate resources for implementing a curriculum based on Universal Design, then teachers can design a course with sensitivity to accessibility, which creates a more inclusive classroom, as opposed to a classroom that is inaccessible with a facade of nondiscrimination tacked on at the end.

Based on the information provided by the Disability Services webpage, SDSU appears to value faculty involvement and recognize the importance of providing its educators with informational resources. The first text that appears under the "faculty" tab reads:

Welcome to the resource page for SDSU Faculty and Staff. We invite you to use these resources to discover opportunities for designing learning environments that 
are inclusive of all students. The content here will provide important information about individuals with disabilities, recommended instructional strategies in the classroom, and creating accessibility in your courses. Our mission at Student Disability Services is to provide mandated accommodations and auxiliary services to students who are registered with SDS and currently enrolled at SDSU. Your participation and collaborative efforts in providing these services is very important in furthering students' academic achievement and success.

This introductory passage implicitly emphasizes the importance of direct, faculty involvement with the opening word, "welcome," and explicitly invites faculty involvement: "Your participation and collaborative efforts in providing these services is very important." By using the second person, singular "you," the passage serves as a direct appeal to each individual reader to play a role in the creation of an inclusive learning environment. The appeal is further emphasized by the use of active verbs such as "discover," "create," "participate," "and collaborate." The use of specific, action words suggests that creating Universal Design on a college campus is an active, ongoing process that requires collaboration and involvement on the part of every member of the faculty.

SDSU's Disability Services website also provides resources on the topics, "Understanding Disabilities," "Instructional Strategies," "Communicating with People with Disabilities," etc. The inclusion of these resources directly and freely accessible on the website provides concrete evidence of the Disability Services Department working toward its values expressed in the welcome message. The parallel between proposed values and taken actions displays reliability to visitors to the website. The placement of resources directly under the welcome message not only conveys reliability, it also evokes 
a sense of immediacy — educating faculty members is necessary and it needs to begin now.

While UCSD has a page dedicated to providing information for faculty members with disabilities which is admirable and fairly progressive, its webpage addressing faculty members in regard to students with disabilities is lacking. The webpage reads:

The Office for Students with Disabilities (OSD) is a resource for the campus community, providing information for and about students and dependents with disabilities. The OSD is responsible for determining eligibility for modifications, adjustments and other accommodations due to a disability. A disability is a medical condition, physical or mental health related, that creates limitations in day-to-day functioning for an individual. All accommodations are determined on a case-by-case basis by the OSD.

The passage is fairly brief and, unlike SDSU's statement, begins and ends with the Office for Students with Disabilities and never directly mentions faculty members or situates faculty members within the "campus community" or the mission of OSD. This passage does not invite faculty members to educate themselves on disabilities. Furthermore, in the event that an enthusiastic faculty member wishes to learn more about disabilities, there are no resources provided directly on OSD's website. The "faculty resources" listed include various forms, lists of staff contacts, a cost collection spreadsheet, and an academic integrity pledge for students to sign which does not include any mention of disabilities and is not clearly related to the Office for Students with Disabilities in any visible way. While UCSD's OSD claims the goal of "providing information for and about 
students and dependents with disabilities," their goal is not supported by any other available information included on the website. 


\section{Conclusions}

Although it would require further study to formulate an educated hypothesis on the reasons for discrepancies in the emphasis placed on Disability Services and opposing ideologies regarding Disability Studies, I find it prudent to propose a possible relationship between college demographics, rankings, and language used to convey Disability Services. UCSD's in-state tuition is over twice as much as SDSU's: $\$ 14,705$ as opposed to SDSU's $\$ 7,084$. There are similar proportions for out-of-state tuition with UCSD at $\$ 41,387$ and SDSU at $\$ 18,244$. The two schools also differ in terms of demographics:

\section{$\underline{\text { SDSU's enrollment by ethnicity }}$}

$35 \%$ White

$27 \%$ Hispanic or Latino

$14 \%$ Asian.

UCSD's enrollment by ethnicity

$54 \%$ Asian

$20 \%$ White,

$16 \%$ Hispanic or Latino.

Additionally, U.S. News and World Report ranks SDSU 146th among national universities and 74th among public schools, whereas it ranks UCSD 44th in national universities and 10th in public schools. SDSU is a less expensive, lower-ranked school with a student body of predominantly White and Hispanic students while UCSD is a more expensive, higher-ranked school with a predominantly Asian and White student body. To speculate possible reasons for this difference between SDSU and UCSD, less 
inclusive language in regard to students of disabilities may be due to a lower number of students with disabilities on campus, either coincidentally or because stigma, the perceived "prestige," or higher cost of tuition serve as barriers for students with disabilities to receive admission. It is also possible that SDSU, which prioritizes providing services to student with disabilities, attracts more students with disabilities to apply for admission, thus continuing the need for effective Disability Services. There is also the possibility that staff and faculty members with more understanding and attention given to disability services gravitate toward the institutions that share similar values. There are many possible explanations for the discrepancy of effectiveness among university Disability Services Departments, however, to move beyond speculation would require further analysis of the ways in which ethnicity and socio-economic status of students and perceived "prestige" of a university affect the availability of disability resources and the rhetorical strategies used to convey information regarding disability on college campuses. It is impossible to make any assertion regarding the underlying causes that influence the variance in rhetorical strategies of disability services before first conducting an empirical study which considers the availability of disability services in relation to university demographics.

Regardless of the reasons behind discrepancies in the language used to discuss disability in academic settings, it is clear that the rhetorical messages convey opposing ideologies regarding disability. By placing information regarding Disability Services on an even level of importance as other university services and using phrases that emphasize the agency of students with disabilities, SDSU displays the value of Universal Design, inclusivity, and educating the whole of a university about disabilities. UCSD focuses on 
accommodations rather than the institutional structures and policies that create obstacles for students with disabilities in the way they explicitly and implicitly separate the Office of Disability Services from disability advocacy and isolate students from the remainder of the university. It is crucial to analyze the merits and shortcomings of existing universities' rhetorical strategies in texts regarding Disability Services in order to thoughtfully reflect on the implicit messages conveyed by information on university websites and intentionally construct future academic policy that is inclusive and aids in creating the most accessible academic environment for all students. Unless taking an active role in the fight for disability services, every member of society is complicit in the marginalization of people with disabilities. 


\section{Works Consulted}

Association on Higher Education and Disability (AHEAD). "Samples." N.p., n.d.

Allen, Caroline "Disability Compliance Draws Scrutiny." The Hoya. N.p., 2015.

Armstrong, Felicity, Derrick Armstrong, and Len Barton. Inclusive Education: Policy, Contexts and Comparative Perspectives. Routledge, 2016.

Bickenbach, Jerome E et al. "Models of Disablement, Universalism and the International Classification of Impairments, Disabilities and Handicaps.” Social Science \& Medicine. vol. 48, no. 9, p. 1173-1187. ScienceDirect, 1999.

Boyle, Coleen A. et al. "Trends in the Prevalence of Developmental Disabilities in US Children, 1997-2008.” Pediatrics. aappublications, 2011.

Brueggemann, Brenda Jo. “An Enabling Pedagogy: Meditations on Writing and Disability." JAC. 2001.

Brueggemann, Brenda Jo. "Becoming Visible: Lessons in Disability.” College Composition and Communication. 2001.

Cherney, James L. “The Rhetoric of Ableism.” Disability Studies Quarterly. vol. 31, no. 3. 2011.

Danforth, Scot. The Incomplete Child: An Intellectual History of Learning Disabilities. Peter Lang, 2009.

"Educational Opportunity Centers.” Program Home Page. N.p., 2016.

Federal Register. “Change in Terminology: 'Mental Retardation' to 'Intellectual Disability." N.p., 2013. 
Feldblum, Chai. "Definition of Disability under Federal Anti-Discrimination Law: What Happened - Why - And What Can We Do about It." Berkeley J. Emp. \& Lab. 2000.

Ferri, Beth A., and David J. Connor. Reading Resistance: Discourses of Exclusion in Desegregation \& Inclusion Debates. Peter Lang, 2006.

Foss, Sonja K. "Framing the Study of Visual Rhetoric: Toward a Transformation of Rhetorical Theory." Defining Visual Rhetorics, ed. Charles A. Hill and Marguerite Helmers. p. 303-313. Routledge, 2004.

Gallagher, Robert P. "National Survey of College Counseling Centers 2014.” Monograph. N.p., 2015.

Gruttadaro, Darcy and Crudo, Dana. College Students Speak: A Survey Report on Mental Health. National Alliance on Mental Illness, 2012.

Hallahan, Daniel P., and Cecil D. Mercer. "Learning Disabilities: Historical Perspectives." Executive Summary. 2001.

Hinshaw, Stephen P. The Mark of Shame: Stigma of Mental Illness and an Agenda for Change. Oxford University Press, 2009.

"Information Required to Be Disclosed Under the Higher Education Act of 1965: Suggestions for Dissemination - A Supplemental Report.”N.p., 2012.

Kadison, Richard. College of the Overwhelmed: The Campus Mental Health Crisis and What to Do about It. Jossey-Bass, 2004.

Kanter, Arlene S., and Ferri, Beth. "Righting Educational Wrongs: Disability Studies in Law and Education." Critical Perspectives on Disability. Syracuse University Press, 2013. 
Lewiecki-Wilson, Cynthia. "Rethinking Rhetoric through Mental Disabilities." Rhetoric Review. vol. 2, p. 156-167. 2003.

Lewin, Tamar. "Harvard and M.I.T. Are Sued Over Lack of Closed Captions." The New York Times. 2015.

Linton, Simi. Claiming Disability: Knowledge and Identity. NYU Press, 1998.

Longo, Judith A. "The Learning Disabled: Challenge to Postsecondary Institutions." Journal of Developmental Education. vol. 3. 1988.

Madaus, Joseph W. “The History of Disability Services in Higher Education.” New Directions for Higher Education 2011. vol. 154, p. 5-15. 2011.

McAlexander, Jason. Personal Interview. 28 Feb. 2017

Mulvany, Julie. "Disability, Impairment or Illness? The Relevance of the Social Model of Disability to the Study of Mental Disorder." Sociology of Health \& Illness. vol. 22, p. 582-601. 2000.

National Center for Educational Statistics (NCES). "Postsecondary Students with Disabilities: Enrollment, Services, and Persistence.” N.p., 2000.

National Center for Educational Statistics (NCES). "Digest of Education Statistics, 2015.” N.p., n.d.

National Center for Educational Statistics (NCES). "Students with Disabilities at DegreeGranting Postsecondary Institutions.” N.p., 2011.

Nelson, Jack Adolph. The Disabled, the Media, and the Information Age. Greenwood Publishing Group, 1994.

Newsom, Walter, and C. Ray Hayes. “Are Mission Statements Worthwhile?” Planning for Higher Education. vol. 19.2, p. 28-30. 1991. 
Oliver, Mike. “The Individual and Social Models of Disability.” N.p., 1990.

Pothier, Dianne, and Devlin, Richard. Critical Disability Theory: Essays in Philosophy, Politics, Policy, and Law. UBC Press, 2011.

Price, Margaret. Mad at School: Rhetorics of Mental Disability and Academic Life. University of Michigan Press, 2011.

Rhodes, Geoffrey. "25 Year History of the IDEA.” Reference Materials. N.p., 2007.

Rusalem, H."The physically handicapped student and the college faculty." College and University. vol. 37, no. 3, p. 161-167. 1962.

Schwarz, Patrick. From Disability to Possibility: The Power of Inclusive Classrooms. Heinemann, 2006.

Scott, S., McGuire, J.M., \& Embry, P. "Universal design for instruction fact sheet." University of Connecticut, Center on Postsecondary Education and Disability, (2002).

SDSU “Student Disability Services” N.p., n.d.

“The Americans With Disabilities Act of 1990.” EEOC, n.d.

Trammell, Jack. "Postsecondary Students and Disability Stigma: Development of the Postsecondary Student Survey of Disability-Related Stigma (PSSDS)." Journal of Postsecondary Education and Disability. vol 22, no. 2, p. 106-116. 2009

U.S. Code 794 "Nondiscrimination under Federal Grants and Programs." LII / Legal Information Institute. N.p., n.d.

U.S. News and World Report. "San Diego State University | SDSU Overall Rankings | US News Best Colleges.” N.p., n.d. 
U.S. News and World Report. "University of California--San Diego | UCSD Overall Rankings | US News Best Colleges.” N.p., n.d.

UCSD “Office for Students with Disabilities.” N.p., n.d.

United States Holocaust Memorial Museum (USHMM). "The Murder of the Handicapped." Holocaust Encyclopedia. N.p., n.d.

Universal Design Learning (UDL). "How Has UDL Been Defined?" National Center On Universal Design for Learning. N.p., n.d.

Wilhelm, Suzanne. "Accommodating Mental Disabilities in Higher Education: A Practical Guide to ADA Requirements." Journal of Law \& Education. vol. 32. N.p., n.d.

Wilson, James C., and Cynthia Lewiecki-Wilson, eds. Embodied Rhetorics: Disability in Language and Culture. Carbondale. Southern Illinois University Press, 2001. 